\title{
Desenvolvimento Curricular e a Dimensão Sociocultural em uma disciplina de Funções na Licenciatura em Educação do Campo
}

\author{
Fernando Luís Pereira Fernandes ${ }^{1}$ \\ Maria do Carmo de Sousa ${ }^{2}$
}

\begin{abstract}
RESUMO
Este artigo tem como objetivo discutir e compreender o desenvolvimento curricular de uma disciplina de funções, na qual foram mobilizados e problematizados aspectos socioculturais relativos à população camponesa. Para isso, tomamos como referência os estudos afins ao Desenvolvimento Curricular e ao Ensino Culturalmente Relevante. A investigação, de natureza qualitativa, foi realizada em uma disciplina de funções em um curso de Licenciatura em Educação do Campo de uma universidade federal, fazendo uso de relatórios e transcrições das falas dos licenciandos. Como resultado, vimos um grande potencial formativo ao organizar o ensino na formação inicial para professores de matemática para escolas do campo, aliado ao Ensino Culturalmente Relevante, permitindo aos licenciandos a tomada de consciência sobre a necessidade de controle financeiro de sua produção agrícola familiar. E, mediante esse controle, repensar a organização da disciplina no Regime de Alternância.
\end{abstract}

PALAVRAS-CHAVE: Formação Inicial de Professores. Ensino Culturalmente Relevante. Currículo de Matemática. Educação Matemática. Formação Matemática do Professor.

Curriculum Development and the Sociocultural Dimension in a Discipline about Function in Rural Education Undergraduate Course

\footnotetext{
1 Doutor em Educação. Universidade Federal do Triângulo Mineiro, Uberaba, Minas Gerais, Brasil. https://orcid.org/0000-0002-8134-5400.fernando.fernandes@uftm.edu.br.

${ }^{2}$ Doutora em Educação. Universidade Federal de São Carlos, São Carlos, São Paulo, Brasil. https://orcid.org/00000002-5523-757X.mdcsousa@ufscar.br.
} 


\begin{abstract}
This article aims to discuss and understand the curricular development of a function discipline, in which socio-cultural aspects related to the peasant population were mobilized and problematized. For that, we take as reference, studies related to Curriculum Development and Culturally Relevant Teaching. The research, of a qualitative nature, was carried out in a function discipline in a Field Education Degree course of a federal university, utilizing reports and transcripts of graduates' speeches. As a result, we saw great formative potential by organizing early-stage teaching for math teachers in rural schools coupled with Culturally Relevant Teaching, allowing undergraduates to become aware of the necessity of financial control of their family farm production. And, through this control, rethink the order of discipline in the Alternation Regime.
\end{abstract}

KEYWORDS: Teacher Initial Education. Culturally Relevant Pedagogy. Mathmatics Curriculum. Mathmatics Education. Mathematical Teacher Education.

$$
* * *
$$

\title{
Introdução
}

A criação de cursos regulares de licenciaturas em Educação do Campo - LECampo - teve início em 2007 com a implementação de um projeto-piloto estruturado com base no Programa de Apoio à Formação Superior em Licenciatura em Educação do Campo - Procampo. Trata-se de uma vitória conquistada pela classe trabalhadora camponesa, que tem lutado pela construção de uma escola do campo, dos trabalhadores (CALDART, 2009).

Essa política pública foi a materialização de uma proposta de formação de professores, visando à superação do modelo até então vigente, a Educação Rural, no qual os valores identitários e culturais dos povos do campo eram invisibilizados, com o desenvolvimento de um ensino pautado no paradigma urbano (ARROYO, 2007) e uma visão estereotipada do sujeito do campo (MUNARIM, 2008).

O projeto-piloto iniciou-se com a oferta de cursos da LECampo por área 
de conhecimento ${ }^{3}$ (Matemática, Ciências da Natureza, Ciências Agrárias, Linguagens e Códigos, e Ciências Humanas e Sociais) em quatro universidades federais, a saber: Universidade Federal de Minas Gerais UFMG -, Universidade de Brasília - UnB -, Universidade Federal de Sergipe - UFS -, e Universidade Federal da Bahia - UFBA.

Além da formação por área de conhecimento, o curso foi organizado em Regime de Alternância, com a demarcação de tempos e espaços formativos, como o Tempo-Escola - período intensivo de estudos na universidade -, e o Tempo-Comunidade - período em que o licenciando continua os estudos em sua comunidade de origem. Não se trata de um modelo de educação a distância, pois o que se vive e se aprende em comunidade também é formativo para o futuro professor em Educação do Campo, cujos saberes locais alimentam o Tempo-Escola e os conhecimentos institucionalizados, o Tempo Comunidade. Sobre isso, concordamos com Antunes-Rocha e Martins (2011), as quais, ao se referirem ao Regime de Alternância, consideram que "a experiência torna-se um lugar com estatuto de aprendizagem e produção de saberes, em que o sujeito conquista um lugar de ator protagonista, apropriando-se individualmente do seu processo de formação" (ANTUNESROCHA; MARTINS, 2011, p. 217).

Como continuidade ao projeto iniciado em 2007, houve a publicação do Edital 02/2012 SESU/SETEC/SECADI/MEC, em 2012, o qual possibilitou a criação de novos cursos de licenciatura em Educação do Campo nas diferentes regiões do Brasil, com a contratação de docentes e técnico-administrativos efetivos por meio da realização de concursos públicos.

Apesar das primeiras experiências nos cursos implementados durante o projeto-piloto e com a oferta de mais vagas em cursos da LECampo, começam a surgir questionamentos e desafios acerca da formação inicial, especialmente em Matemática, na perspectiva de levar em conta uma organização e desenvolvimento curricular diferente do modelo presente nos

\footnotetext{
${ }^{3}$ Ressaltamos a existência de cursos que ofertam, por exemplo, a Habilitação em Ciências da Natureza e Matemática.
} 
demais cursos de licenciatura em Matemática, questões essas levantadas no início de nossa investigação:

Como contribuir para a formação de professores, mais especificamente, em Educação do Campo? Em particular, como formar professores para escolas do campo, habilitados em Matemática, que atendam às demandas dessas escolas e de suas comunidades? Que currículo contemplar na formação inicial de professores? Seria possível estabelecer relações entre saberes cotidianos e saberes científicos em uma disciplina desse curso? Como tratar esses saberes cotidianos, locais, no programa curricular dos cursos de formação inicial? Que relações estabelecer entre os conteúdos das funções matemáticas e as questões do campo? Que matemáticas poderiam/deveriam ser abordadas e/ou problematizadas? (FERNANDES, 2019, p. 26)

Em face das questões apresentadas anteriormente, focaremos aquelas pertinentes ao currículo de uma disciplina de formação matemática. Por se tratar de um recorte de uma pesquisa concluída de Doutorado, temos como objetivo deste artigo discutir e compreender o desenvolvimento curricular de uma disciplina de funções, na qual foram mobilizados e problematizados aspectos socioculturais relativos à população camponesa. Nessa disciplina, a nossa preocupação foi, além de desenvolver e revisitar conteúdos matemáticos atinentes ao conceito de função, supondo que esses tenham sido estudados durante o Ensino Médio, levantar e problematizar elementos sociais e culturais do campo, ações entendidas por nós como um dos aspectos que diferenciam a LECampo Habilitação em Matemática das demais licenciaturas, presenciais ou a distância.

Como indicam os resultados de investigação realizada por Sachs e Elias (2016), as LECampo têm valorizado a Matemática Acadêmica, ou Científica, na formação matemática do futuro professor e desconsiderado a dimensão sociocultural camponesa. Diante disso, vemos como relevante e emergente 
considerar práticas formativas nos cursos de licenciatura em Educação do Campo que reconheçam, valorizem e abram espaço para os modos de vida da população camponesa de modo que esses adentrem os muros da universidade e estabeleçam relações e aproximações entre saberes locais e conhecimentos matemáticos.

$\mathrm{Na}$ seção a seguir, apresentamos os referenciais teóricos que embasam a pesquisa: desenvolvimento curricular e prática de ensino culturalmente relevante.

\section{Referencial teórico}

Ao buscarmos uma definição para a palavra currículo, percebemos a ambiguidade e a complexidade de explicitar, em poucas palavras, o seu significado (PACHECO, 2005). Para além de uma concepção tradicionalista e dicionarizada do termo, aludindo-se à noção de programa - que também constitui a compreensão desta expressão -, ou seja, referindo-se ao currículo prescrito (SACRISTÁN, 2000), Pacheco (2005) considera o fazer pedagógico da sala de aula - o currículo em ação (SACRISTÁN, 2000) - como uma dimensão que contribui para definir o que vem a ser currículo, afirmando que:

Currículo é também um projecto, uma práxis sobre um conhecimento controlado, por um lado, "no contexto social em que o conhecimento é concebido e conhecido" e, por outro, no modo "como esse conhecimento é traduzido para ser utilizado num determinado meio educativo" (PACHECO, 2005, p. 42, aspas do autor).

Ao examinar a prática e sua problemática, o autor ressalta a necessidade de levar em conta elementos epistemológicos, políticos, econômicos, ideológicos, técnicos, estéticos e históricos, constituintes do currículo.

Assim, a organização do ensino, a seleção de materiais e recursos, o 
planejamento, a implementação e o processo de avaliação são parte do desenvolvimento curricular, no qual o professor opta por caminhos metodológicos, e não outros, com base em documentos referenciais e em suas concepções e crenças sobre o ensino dos conteúdos escolares.

No que tange ao desenvolvimento curricular em Matemática, no contexto da Educação Básica, Januário, Lima e Traldi Junior (2014) discutem as práticas dos professores que ensinam matemática e a gestão do currículo. Os autores apresentam questionamentos acerca do fazer pedagógico em matemática, problematizando o que os alunos necessitam aprender nessa disciplina, mostrando que um dos objetivos do desenvolvimento curricular é "levar os alunos para a tomada consciente e crítica de decisões" (JANUÁRIO, LIMA, TRALDI JUNIOR, 2014, p. 49), pressupondo, inclusive, diferentes modalidades de ensino e suas especificidades, a saber: Ensino Fundamental, Ensino Médio, Educação de Jovens e Adultos, Educação Quilombola, Indígena e do Campo.

Os autores apontam para a necessidade de se considerar o currículo e o desenvolvimento curricular como "eixos estruturantes da formação de professores” (JANUÁRIO, LIMA, TRALDI JUNIOR, 2014, p. 54) e ressaltam a importância da contextualização do saber, não somente "no sentido de se fazer relações com as atividades cotidianas dos alunos, mas, também, buscar significar o saber matemático por meio da contextualização dentro da Matemática." (JANUÁRIO, LIMA, TRALDI JUNIOR, 2014, p. 55).

$\mathrm{Na}$ busca por clarear os aspectos curriculares no Ensino Superior, especialmente no contexto de formação de professores de matemática para escolas do campo, entendemos pertinente a discussão e problematização do contexto camponês nessa modalidade de licenciatura, sobretudo em disciplinas de formação matemática (MOREIRA; DAVID (2005); FIORENTINI; OLIVEIRA (2013)).

Barbosa (2014) buscou compreender o currículo de cursos de licenciatura em Educação do Campo mediante a análise dos projetos pedagógicos de curso e entrevistas com pessoas envolvidas com a temática. Os 
resultados obtidos revelaram quatro modos de organização e compreensão a respeito do papel da matemática nesses currículos dessas licenciaturas: (1) ao tomar como ponto de partida e referência a realidade, as escolas do campo devem contemplar os mesmos conteúdos das demais escolas; (2) diferente da primeira, essa almeja promover questionamento do currículo de matemática e levar em conta os saberes locais alusivos à cultura camponesa, no intuito de superar a condição marginal a que a escola do campo foi conduzida; (3) avaliase que não deveria haver diferenças entre o currículo de matemática para escolas do campo e as demais escolas e, para finalizar; (4) a necessidade de as escolas do campo ofertarem cursos técnicos e profissionalizantes para os seus estudantes.

Após o trabalho de Barbosa (2014), o qual nos indica um panorama dos programas curriculares de alguns cursos da LECampo, Sachs e Elias (2016) aprofundam essa discussão focalizando a formação matemática nas LECampo. Os autores detiveram-se em oito cursos dessas licenciaturas e analisaram três aspectos dos projetos pedagógicos de curso - PPC: os objetivos do curso, o perfil do egresso e as ementas das disciplinas. Concluíram que há uma ênfase na matemática acadêmica, bem como, nas componentes que tratam dos conteúdos matemáticos, não há uma articulação desses com a dimensão sociocultural.

Lima e Lima (2017) também ressaltam o desafio das instituições que ofertam essa modalidade de licenciatura com propostas curriculares em que as dimensões social, cultural e política sejam contempladas nas disciplinas de formação matemática.

Nota-se a relevância de agregar as dimensões socioculturais na formação inicial de professores em Educação do Campo. Mas, sobretudo questiona-se, como proceder nesse sentido? Como poderia ser realizado esse processo de contextualização em uma disciplina de formação matemática em um curso de licenciatura em Educação do Campo?

Um caminho que compreendemos ser viável para o desenvolvimento curricular seria priorizar os elementos característicos de um Ensino 
Culturalmente Relevante. Ladson-Billings (2008) discute a valorização da história e da cultura afro-americana em práticas pedagógicas ambientadas em classes do Ensino Fundamental, mediante um ensino de excelência, colaborando para que os estudantes estejam aptos a estabelecer "conexões entre sua comunidade, identidade nacional e global" (LADSON-BILLINGS, 2008 , p. 67). Em outras palavras, que sejam discutidos os aspectos sociais, culturais e históricos da população, "preservando uma identidade positiva como afro-americanos" (LADSON-BILLINGS, 2008, p. 30).

Julgamos que o Ensino Culturalmente Relevante pode ser aproveitado em outros contextos, como o da Educação do Campo, tendo em vista os pressupostos e especialidade da formação de professores nessa licenciatura, principalmente quando se trata de justiça social. Para exemplificar, no Edital 02/2012 SESU/SETEC/SECADI/MEC, concernente à criação de 42 cursos de licenciatura em Educação do Campo, justifica-se a criação desses como ação afirmativa:

os Projetos deverão contemplar alternativas de organização escolar e pedagógica, por área de conhecimento, contribuindo para a expansão da oferta da educação básica nas comunidades rurais e para a superação das desvantagens educacionais históricas sofridas pelas populações do campo, tendo como prioridade a garantia da formação inicial de professores em exercício nas escolas do campo que não possuem o Ensino Superior. (MEC, 2012, p.1, grifo nosso).

Outro aspecto do Ensino Culturalmente Relevante frisado como fundamental é a tomada de consciência dos estudantes quanto à problematização de situações, as quais concernem a aspectos sociais, culturais e identitários. Para Ladson-Billings (2008), é papel do Ensino Culturalmente Relevante causar estranhamento nos estudantes e consequentemente levá-los a questionar sua própria realidade.

Especialmente na Educação Matemática, Rosa e Orey (2018, p. 19), ao 
se referirem a um currículo de matemática culturalmente relevante, enfatizam que essa disciplina "é ensinada em um contexto significativo em que os alunos têm oportunidades de relacionar novos conteúdos e experiências de aprendizado com os conhecimentos e habilidades adquiridos no ambiente escolar". Ao tomarem como fundamento os pressupostos do Programa Etnomatemática, salientam que

[...] um currículo matemático concebido em uma perspectiva etnomatemática auxilia no desenvolvimento de conceitos e práticas matemáticas que se originam na cultura estudantil, conectando-os à matemática acadêmica, pois o entendimento da matemática escolar contribui para uma compreensão mais ampla dos princípios matemáticos culturais (ROSA; OREY, 2018, p.19).

Assim, diante do exposto, vemos como imprescindível empreender investigações que contemplem o desenvolvimento curricular na formação inicial de professores de matemática para escolas do campo, na tentativa de articular os conhecimentos matemáticos e a dimensão sociocultural dos licenciandos do campo.

$\mathrm{Na}$ seção a seguir, apresentamos os aspectos metodológicos da investigação, bem como os instrumentos de produção de dados e categoria de análise construída.

\section{Metodologia e o contexto de produção de dados}

A metodologa empregada na investigação é de natureza qualitativa, sobretudo interpretativa (BOGDAN; BIKLEN, 1994). Trata-se de uma investigação naturalista ou de campo, em virtude de a pesquisa ter ocorrido "diretamente no local em que o problema ou fenômeno acontece" (FIORENTINI; LORENZATO, 2007, p. 106). 
A produção de dados deu-se no âmbito da disciplina Funções e suas Aplicaçoes no Campo Agrário, a qual foi ministrada pelo primeiro autor deste artigo, docente da Universidade Federal do Triângulo Mineiro, localizada no município de Uberaba, MG. Os participantes ${ }^{4}$ da investigação foram 45 licenciandos em Educação do $\mathrm{Campo}^{5}$, regularmente matriculados na disciplina de Funções, cuja oferta é proporcionada no segundo período do curso. Esses licenciandos, em sua maioria, eram oriundos da região norte do estado de Minas Gerais. Em menor quantidade, contamos com estudantes da região do Triângulo Mineiro e da região noroeste do mesmo estado.

Trata-se de uma investigação NA prática pedagógica da formação inicial de professores, pois não houve a preocupação de investigar e compreender as aprendizagens do professor formador.

Os instrumentos utilizados foram a gravação das aulas em vídeo e registros escritos dos licenciandos. Para a análise dos dados, contamos com as produções escritas dos estudantes e a transcrição dos diálogos das aulas.

A disciplina possuía carga horária de 60 horas-aula a serem desenvolvidas no Tempo-Escola e 30 horas-aula a distância. Destaca-se que não há no Projeto Pedagógico do Curso menção à carga horária destinada ao Tempo-Comunidade. A ementa da disciplina era a seguinte: Conjuntos e suas operações. Relações. Função Afim e Quadrática. Funções exponenciais e logarítmicas. Funções compostas e inversas. Função modular. Aplicações no campo agrário.

Nota-se que a ementa possui conteúdos matemáticos presentes no Ensino Médio e, do modo que compreendemos, espera-se que a abordagem procure revisitar temas já estudados pelos estudantes, mas que, no contexto da formação inicial, abarque ainda a dimensão do futuro professor de matemática para a escola do campo.

A ementa expõe os temas a serem desenvolvidos e somente estabelece

\footnotetext{
${ }^{4}$ O projeto de pesquisa foi aprovado pelo Comitê de Ética e Pesquisa da UFSCar e todos os licenciandos aderiram à participação do processo de produção de dados da investigação, mediante concordância e assinatura do Termo de Consentimento Livre e Esclarecido.

${ }^{5}$ Os nomes dos licenciandos são fictícios e foram escolhidos por eles.
} 
conexões com o contexto camponês no item Aplicações no campo agrário. Do modo que se apresenta, abre-se para um espectro de possibilidades, como, por exemplo, situações-problema específicas de um curso de Agronomia, como a produtividade de uma determinada plantação ou lavoura, as quais não refletem a necessidade de formação nessa licenciatura.

A disciplina de Funções foi estruturada na Metodologia de Resolução de Problemas. Entretanto, dos dez encontros de 6 horas-aula cada um, nos segundo e terceiro realizamos a dinâmica Atividades Profissionais e a Matemática, cujo objetivo era conhecer os licenciandos, a sua origem e suas atividades profissionais, além de possibilitar uma aproximação dos modos de vida do campo a alguns licenciandos que não residem e não vivem de atividades vinculadas ao campo.

No início do encontro, registramos no quadro o seguinte enunciado: Descrever, de maneira detalhada, as práticas matemáticas presentes em sua atividade profissional, identificando as grandezas envolvidas.

Surpreendemo-nos com as produções dos estudantes, pois, dos 22 relatórios produzidos, 12 deles vieram na forma de problemas matemáticos. Apesar de inesperado, vimos como significativo potencializar na prática formativa dos licenciandos uma discussão e problematização em torno dos problemas formulados.

Sobre a formulação de problemas, Ticha e Hospesová (2013) destacam as potencialidades dessa abordagem metodológica no contexto da formação de professores para os anos iniciais, mediante discussão e reflexão dos problemas levantados e suas resoluções, no intuito de explorar os seus conteúdos matemáticos.

Chica (2001) aproveita a complexidade da formulação de problemas como um modo de aproximar e estabelecer relações entre a língua materna e a matemática, priorizando na formação dos estudantes a construção de conjecturas e o desenvolvimento da comunicação e argumentação matemáticas.

Em contexto de formação continuada, Fernandes e Fernandes (2017) 
explicitam diversos conhecimentos quanto à prática dos professores participantes, em um ambiente de formulação de problemas e com base na Simetria Invertida (MELLO, 2001).

Diante desse contexto e, após a organização dos dados, construímos uma categoria analítica - a tomada de consciência dos licenciandos nas aulas de matemática -, a qual será discutida a seguir.

\section{Análise dos dados}

Como parte da turma concebeu problemas matemáticos vinculados às atividades profissionais no campo, escolhemos a questão elaborada por Bruno e Mariana, na qual a dupla desconsidera os custos de mão de obra em certos trabalhos, postura que nos deixou intrigados por não ter sido um caso isolado:

Quero cultivar uma área de 0,6ha com plantio de milho. Considerando as orientações técnicas de plantio, 5 sementes $/ \mathrm{m}^{2}$, com adubação de plantio de $40 \mathrm{~g} / \mathrm{m}^{2}$ e duas adubações de cobertura em quantidade de $20 \mathrm{~g} / \mathrm{m}^{2}$. O preço de um saco de sementes contendo 60000 sementes é de $\mathrm{R} \$ 300,00$; o adubo de plantio de 50kg custa $\mathrm{R} \$ 95,00$ e o adubo de cobertura, $\mathrm{R} \$ 110,00$. Sem levar em conta as despesas com mão de obra, qual será o custo da minha produção?

Segue a resolução na figura a seguir: 
FIGURA 1: Resolução do problema de Bruno e Mariana

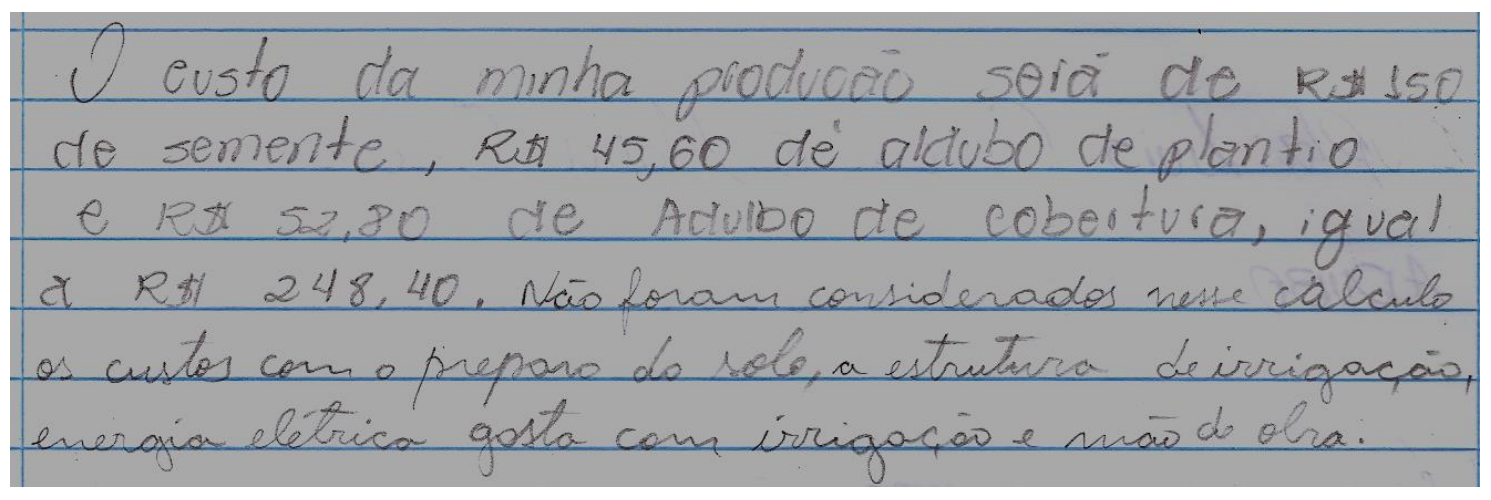

Fonte: Arquivo do pesquisador.

O problema elaborado visa obter o custo da produção de milho em uma área disponível no lote em que Bruno reside fazendo um levantamento das despesas dos insumos requeridos para o plantio. A dupla destacou, tanto na questão como na resolução, que não foram levados em conta os cálculos afins à mão de obra, constatando-se, inclusive, uma caligrafia diferente na resolução para dar destaque ao trecho.

O licenciando Bruno, logo após a aula de formulação e resolução de problemas - e antes da socialização com as demais duplas da classe -, compartilhou conosco o fato de nunca haver realizado o controle de custos e receitas de sua produção agrícola, e acabou confessando que se encontrava em um quadro de endividamento bancário, em razão de empréstimos e uso do limite do cheque especial.

Possivelmente, por não conhecer os produtos financeiros disponíveis em sua conta corrente, encontrou-se nessa condição. No momento de socialização dos problemas formulados, Bruno reforçou o que havia nos falado reservadamente sobre a ausência de controle financeiro da produção:

[...] estava até comentando com o Fernando, isso é coisa que geralmente a gente não faz. Mas a gente tem que fazer porque senão... não consegue ter uma estimativa da realidade, do que vale a pena e do que não vale a pena (Fala do estudante Bruno durante a socialização, grifo nosso). 
Bruno enfatiza que o controle financeiro da produção é algo que geralmente a gente não faz, generalizando, no entanto, que isso constitui um hábito ou característica da população camponesa na previsão de quanto vai faturar, quando vai colher e comercializar os seus produtos.

Corroborando com a fala de Bruno, o licenciando Pedro também se manifestou na socialização dos problemas formulados:

[...] a gente vai calcular quantos pés de mandioca é possível plantar em um hectare de terra, um hectare de roça. Eu creio que a maioria do pessoal que planta nunca fez esse cálculo, como eu também não tinha feito. Então assim eu falei 'vamos fazer uma curiosidade aqui, pra ter uma noção. E fiquei surpreso com a quantidade de pés de mandioca que cabem dentro de um hectare (Fala do estudante Pedro durante a socialização, grifo nosso).

Na mesma perspectiva, a licencianda Mariana, menos comunicativa que seu colega de dupla, expressou-se por escrito a respeito do assunto na avaliação da dinâmica:

Não foi muito difícil, pois meu pai já trabalha e planta com isso e eu já tive a experiência quando era mais nova de ter ajudado ele a plantar. Só nunca parei para pensar quanto ele gastaria ao todo. (Avaliação da dinâmica Atividades Profissionais, estudante Mariana, grifo nosso)

Em decorrência dos dados explicitados, podemos inferir que as famílias dos licenciandos participantes da investigação não têm o hábito de praticar o controle financeiro dos custos e receita de sua produção agrícola, não do modo convencional, com o registro escrito de despesas e faturamento da produção em planilhas e tabelas. Apesar de algumas duplas terem demonstrado os custos atinentes às suas produções, a nós nos pareceu mais que eles sentiram 
a necessidade de cumprir uma tarefa solicitada na aula de matemática, dando a entender que não é uma prática corriqueira em seu ambiente familiar. Os seus registros e falas denotam um aspecto da cultura camponesa sobre a condução financeira de sua produção e, por que não, familiar, tendo em vista que se trata de uma produção agrícola pequena, para a subsistência e a comercialização de poucos itens excedentes.

Para contribuir na compreensão do caso, em outro momento da investigação, aplicamos aos participantes um questionário de natureza socioeconômica. Descobrimos que $80 \%$ dos pais e $71 \%$ das mães dos participantes da pesquisa não concluíram o Ensino Fundamental. Em princípio, podemos deduzir que a pouca escolaridade dos pais pode ser um fator a ser considerado na análise desse episódio. Porém, os participantes da pesquisa possuem Ensino Médio completo e estão matriculados em um curso de graduação. Ou seja, não seria apenas uma questão de dominar ou não conhecimentos matemáticos a respeito das finanças pessoais e da produção agrícola.

Julgamos que se trata de um elemento cultural próprio dessa população em especial, que não adota o registro escrito do controle financeiro de sua produção agrícola, mesmo que seja pequena. Contudo, pelos limites da investigação, seus objetivos e instrumentos de produção de dados, não tivemos condições de tentar compreender o modo de organização dessa população sobre o controle financeiro. É possível, também, que durante o processo de produção de dados - as aulas da disciplina de Funções -, não tenhamos construído uma relação de confiança mais sólida com os licenciandos, e, como modo de resistência e preservação de seus modos de vida, eles não teriam expressado as maneiras próprias de como lidam com as questões financeiras.

Assim, ao abordar essas questões nas aulas da disciplina de Funções, foi possível promover uma tomada de consciência desses estudantes (LADSON-BILLINGS, 2008) a respeito de sua vida financeira, pois, previamente à realização da tarefa, era natural para eles não planejar o controle das finanças, atingindo-se um dos objetivos do desenvolvimento 
curricular (JANUÁRIO, LIMA, TRALDI JUNIOR, 2014). Como consequência desse desconhecimento, em nossa interpretação, os estudantes e seus familiares poderiam ser enganados em situações de comercialização de seus produtos, como a da mandioca in natura ou de polvilho para pequenas indústrias da região por um valor inferior ao praticado no mercado, visto que, sem a contabilização dos gastos, pode não se identificar se houve compensação dos investimentos.

Na busca por aprofundar os conteúdos matemáticos sobre funções nas atividades profissionais do campo praticadas pelos licenciandos, no encontro seguinte houve a proposição de problemas pelas duplas que não o fizeram e, para todas as duplas, a representação das situações-problema em distintas formas: na língua materna (pelo enunciado), tabular, gráfica e algébrica e, diante dessa representações, poder inferir, por exemplo, o ponto de equilibro entre custo e receita.

Sem dúvida, para a implementação da ementa da disciplina, essas situações não seriam suficientes e, por isso, houve uma ampliação de situações-problema e de temáticas pertinentes aos futuros professores de matemática para escolas do campo a serem desenvolvidas no Tempo-Escola.

\section{Considerações finais}

Conforme explicitado no início do artigo, propusemos como objetivo discutir e compreender o desenvolvimento curricular de uma disciplina de funções, na qual foram mobilizados e problematizados aspectos socioculturais relativos à população camponesa. A organização do ensino, a gestão da aula e a intencionalidade do professor permitiram um incremento curricular para além do que constava na ementa da disciplina e que, em nossa compreensão, atende ao que se espera na formação de professores de matemática para escolas do campo.

Não temos dúvida de que, tomando como base os pressupostos do Ensino Culturalmente Relevante, foi possível esquematizar e perceber 
aspectos sociais, culturais e identitários dos licencandos em Educação do Campo. A tomada de consciência dos licenciandos sobre práticas cotidianas por eles naturalizadas ensejou uma discussão sobre uma possível exploração a que estariam submetidos, tanto eles como seus familiares, quando da comercialização dos seus produtos.

Mediante a apresentação e exame dos dados, vimos como imprescindível cogitar uma prática na formação inicial de professores de matemática para escolas do campo, na qual seriam versados e problematizados aspectos da dimensão sociocultural do campo em uma disciplina de formação matemática.

Esta experiência investigativa, na tentativa de proporcionar em uma aula de conteúdo matemático a discussão e questionamento de aspectos da cultura camponesa, possibilitou, inclusive, repensar a própria organização dos tempos e espaços formativos do curso, o Tempo-Escola e TempoComunidade, bem como o papel da disciplina de Funções.

Nesse sentido, propomos que essa disciplina possa ter parte de sua carga horária incluída em Tempo-Comunidade, no intuito de propiciar situações formativas aos estudantes que, desse modo, poderiam estabelecer relações entre os conhecimentos matemáticos revisitados (ou aprendidos) na universidade e temáticas pertinentes e problematizadoras vividas em comunidade.

Ao considerarmos o Regime de Alternância como organizador dos tempos e espaços formativos na LECampo, deparamos com a oportunidade de readequação dos papéis dos conhecimentos matemáticos ensinados na academia na interface com os saberes matemáticos praticados pelos licenciandos, contribuindo assim na formação do professor de matemática para escolas do campo.

\section{Referências}

ANTUNES-ROCHA, M. I.; MARTINS, M. F. A. Diálogo entre teoria e prática na 
Educação do Campo: Tempo Escola/ Tempo Comunidade e alternância como princípio metodológico para organização dos tempos e espaços no curso de Licenciatura em Educação do Campo. In: MOLINA, M. C.; SÁ, L. M. Licenciaturas em Educação do Campo: registros e reflexões a partir das experiências piloto. Belo Horizonte: Autêntica, 2011, p. 213-228

ARROYO, M. G. Políticas de formação de educadores (as) do campo. Cad. CEDES, Campinas, v.27, n.72, p.157-176, 2007. Disponível em: $<$ http://www.scielo.br/pdf/ccedes/v27n72/a04v2772.pdf >. Acesso em: 02 fev. 2016.

BARBOSA, L. N. S. C. Entendimentos a respeito da matemática na educação do campo: questões sobre currículo. 2014. 234 p. Tese (Doutorado em Educação Matemática) - Instituto de Geociências e Ciências Exatas, Universidade Estadual Paulista "Julio de Mesquita Filho", Rio Claro, 2014.

BOGDAN, R.C.; BIKLEN, S.K; Investigação Qualitativa em Educação. Porto: Porto Editora, 1994.

CALDART, R. S. Educação do Campo: notas para uma análise de percurso. Trab. Educ. Saúde, Rio de Janeiro, v.7, n.1, p.35-64, 2009.

CHICA, C. Por que formular problemas? In: SMOLE, K. S, DINIZ, M. I. Ler, escrever e resolver problemas: habilidades básicas para aprender matemática. Porto Alegre: Artmed, 2001, p.151-173.

FERNANDES, F. L. P. Práticas de letramento de professores de matemática em formação na licenciatura em educação do campo. 2019. 230 p. Tese (Doutorado em Educação) - Centro de Educação e Ciências Humanas, Universidade Federal de São Carlos, São Carlos, 2019.

FERNANDES, F. L. P.; FERNANDES, L. F. B. A formulação de problemas matemáticos em um espaço de formação continuada de professores dos anos iniciais. \#Tear: Revista de Educação, Ciência e Tecnologia, Canoas, v.6, n. 1, p.1-13, 2017. Disponível em: <http://periodicos.ifrs.edu.br/index.php/tear/article/view/2128/1554> Acesso em: 01 ago.2017.

FIORENTINI, D.; LORENZATO, S. Investigação em Educação Matemática: percursos teóricos e metodológicos. 2. ed. Campinas: Autores Associados, 2007.

FIORENTINI, D.; OLIVEIRA, A. T. C. C. O lugar das matemáticas na Licenciatura em Matemática: que matemáticas e que práticas formativas?. Bolema, Rio Claro, v. 27, n. 47, p. 917-938, 2013. Disponível em: $<$ http://www.scielo.br/scielo.php?script=sci_arttext\&pid=S0103636X2013000400011\&lng=en\&nrm=iso >. Acesso em: 01 mar.2017.

JANUÁRIO, G.; LIMA, K.; TRALDI JUNIOR, A. Desenvolvimento curricular e prática pedagógica em educação matemática. Revista Iluminart, n. 12, p. 44-56, 2014. Disponível em: http://revistailuminart.ti.srt.ifsp.edu.br/index.php/iluminart/article/view/208/247> Acesso em: 01 set.2019. 
LADSON-BILLINGS, G. Os guardiões de sonhos: o ensino bem-sucedido de crianças afro-americanas. Belo Horizonte: Autêntica, 2008.

LIMA, A. S.; LIMA, I. M. S. Formação de Professores de Matemática na Licenciatua em Educação do Campo: um olhar sobre as pesquisas. Rematec, n. 25, 54-69, 2017. Disponível em: <http://www.rematec.net.br/index.php/rematec/article/view/99/76>. Acesso em: 01 mar.2019.

MEC. Edital 02/2012 SESU/SETEC/SECADI/MEC. Chamada Pública para seleção de Instituições Federais de Educação Superior-IFES e de Institutos Federais de Educação, Ciência e Tecnologia-IFET, para criação de cursos de Licenciatura em Educação do Campo, na modalidade presencial. 2012. Disponível em: $<$ http://portal.mec.gov.br/index.php?option=com_docman\&view=download\&alias $=1$ 3300-edital-02-2012-sesu-setec-secadi-31-agosto-2012-pdf\&category_slug=junho2013-pdf\&Itemid=30192> Acesso em: 12 ago.2015.

MELLO, G. N. Formação inicial de professores para a educação básica: uma (re)visão radical. Revista Iberoamericana de Educación, n.25, p. 147-174, 2001.

MOREIRA, P. C. DAVID, M. M. S. A formação matemática docente: licenciatura e prática docente escolar. Belo Horizonte: Autêntica, 2005.

MUNARIM, A. Movimento nacional de educação do campo: uma trajetória em construção. In: Reunião Anual da ANPEd, 31, 2008, Caxambu. Anais... Caxambu: ANPEd, 2008, p. 1-17.

PACHECO, J. A. Escritos Curriculares. São Paulo: Cortez, 2005.

ROSA, M.; OREY, D. C. Conectando a Etnomatemática e a Pedagogia Culturamente Relevante na Educação Matemática para a Promoção da Justiça Social. Rematec, n. 25, p. 6-23. 2018. Disponível em: $<$ http://www.rematec.net.br/index.php/rematec/article/download/143/125>. Acesso em: 01. Ago.2019.

SACHS, L.; ELIAS, H. R. A Formação Matemática nos Cursos de Licenciatura em Educação do Campo. Bolema, Rio Claro, v.30, n. 55, p. 439-454, 2016. Disponível em: $<$ http://www.scielo.br/pdf/bolema/v30n55/1980-4415-bolema-30-55-0439.pdf $>$ Acesso em: 22 nov.2019.

SACRISTÁN, J. G. O currículo: uma reflexão sobre a prática. 3. ed. Tradução: Ernani F. da Fonseca Rosa. Porto Alegre: Artmed, 2000.

TICHÁ, M.; HOSPESOVÁ, A. Developing teacher's subject didactic competence through problem posing. Educational Studies in Mathematics, v. 83, n.1, p. 133-143, 2013. 